\title{
Financial incentives to reduce female infanticide, child marriage and promote girl's education: impact
}

\author{
Huma Haider \\ Independent consultant \\ 11 December 2020
}

\section{Question}

What are the key design features and impact of programmes that use CCTs or baby bonds to reduce female infanticide, child marriage and promote girl's education? Consider the impact on individual or family outcomes, gender and wealth equality or unintended consequences of the interventions. Focus on South Asia and other LMICs.

\section{Contents}

1. Summary

2. Background

3. Programme design

4. Programme outcomes - short and medium-term

5. Programme outcomes - longer-term equality

6. Unintended consequences of programmes

7. References

The K4D helpdesk service provides brief summaries of current research, evidence, and lessons learned. Helpdesk reports are not rigorous or systematic reviews; they are intended to provide an introduction to the most important evidence related to a research question. They draw on a rapid deskbased review of published literature and consultation with subject specialists. 


\section{Summary}

Son preference and male-skewed sex ratio at birth is well documented in Asia (Kim, 2020). In contexts where parents strongly prefer sons to daughters, they may seek to deal with unwanted daughters through child-bride marriage, female infanticide, or sex-selective abortion (Suarez, 2018). Conditional cash transfer (CCT) schemes have been adopted to promote the survival and well-being of girls (Sekher, 2015). They provide parents with financial incentives to raise daughters; to delay marrying them until age 18; and to reduce the gender imbalance in school.

Given that many CCT programmes aimed at addressing girl children are relatively new, it has in many cases been too early to evaluate their effectiveness. There is thus limited evidence of the impact of their implementation and outcomes (Sekher \& Ram, 2015). This helpdesk report focuses on recent studies, published in the past five years, on select programmes implemented in South Asia, particularly in India, for which there is the most available information. Evidence suggests that CCT programmes aimed at supporting the girl child have succeeded in promoting school enrolment and delaying marriage in South Asia. It is less clear, however, the extent to which these transfers have affected gender-biased sex selection (Jejeebhoy et al., 2015).

\section{Programme outcomes - short and medium-term}

Sex selection:

- Apni Beti Apna Dhan (ABAD) (Haryana, India) aimed to enhance the value of girls. Improvements in the survival rate of girl children during 1993-2006 were higher among those eligible for the scheme (Krishnan et al., 2014).

- By contrast, recent research by the Population Council on interventions against sex selection, including CCTs in two districts of Haryana, finds no strong signs that CCTs reduce sex-selective behaviour (see Rahm, 2020).

- Devi Rupak programme (Haryana, India) seeks to lower fertility and the sex ratio at birth. A study finds that while fertility decreases, the sex ratio at birth worsens as families with high son preference are unwilling to forgo a son, despite significantly higher benefits for a daughter (Anukriti, 2016).

- Pro-natalist cash programmes in South Korea, designed to increase fertility instead, unintentionally alleviated sex ratio imbalance (Kim, 2020).

\section{Child marriage:}

- Dhanlakshmi programme (India) offered staggered financial incentives to encourage retaining and educating daughters; and preventing child marriage. Seventy-eight percent of beneficiary parents stated that even if they were to get a good marriage proposal for their daughter, they would not arrange her marriage until she is 18 (Sekher and Ram, 2015, 95).

- These changes in parental attitudes may stem not only from the conditionality to delay marriage, but also from the requirement to continue girls' education up to a certain level, which indirectly delays their marriage (Sekher \& Ram, 2015).

- Similarly, the Female Secondary School Stipend Programme (Bangladesh), which offered financial incentives to promote the education of girls, had a significant effect on delaying age of marriage (see Field et al., 2018). 
- Save the Children's girls' empowerment programme (Bangladesh) offered conditional stipends to families of teenage girls, reducing the likelihood of girls being married under age 18 by 22 percent and, in turn, improving their enrolment in education (Field et al., 2018, i)

- Research on the Punjab Female School Stipend Programme (FSSP) (Pakistan) also finds that participant girls delay marriage by over a year (Alam et al, 2011).

- In contrast, an evaluation of the ABAD programme finds that participation in the programme had no effect on the probability of marriage before age 18, reflective of an overall trend toward later age of marriage in Haryana (Nanda et al., 2016).

\section{Education:}

- While CCTs targeting education of girls can contribute to delay in marriage, financial incentives to counter child marriage can also influence outcomes in the education of girls.

- CCT programmes targeting girls' education have had a positive impact in reducing the gender imbalance in enrolment and retention of girls in schools (Sekher \& Ram, 2015).

- Being a Dhanlakshmi scheme beneficiary increased the probability of being in school by 10 percent and parental intention of educating their daughters past tenth standard by 13 percent (in comparison to non-beneficiaries) (Sekher \& Ram, 2015, 89).

- In contrast, the ABAD programme has no evident effect on marriage before the age of 18 . Nonetheless, it demonstrates that a CCT programme to delay the age of marriage can still improve educational outcomes for girls, with ABAD beneficiaries 23 percent more likely to be in school after age 15 (Nanda et al., 2014, 7).

- The FSSSP increased the likelihood of eligible women completing secondary school or beyond, with exposure to the programme increasing years of schooling for female students by 0.6 to 1.2 years (Hahn et al., 2018, 410).

- The FSSP increased enrolment of eligible girls in middle school by nearly 9 percentage points, with participating girls delaying their marriage by 1.4 years (Alam et al., 2011).

\section{Programme outcomes - longer-term}

Greater value given to girls; changes in attitudes and treatment of girls:

- There is evidence that financial incentives are making girls much more valuable (Rahm, 2020). Data from the Dhanlakshmi scheme indicates that most beneficiary families felt 'less burdened' to have girls, contributing to girls being treated and valued better in beneficiary households than in non-beneficiary families (Sekher \& Ram, 2015).

- There is no evidence, however, that such programmes have changed families' preference for girl children or achieved transformational changes in the treatment of girl children (Sekhar \& Ram, 2015; Endow et al., 2015; Krishnan et al., 2014). There is thus a risk that once incentives are removed, families will revert to valuing sons over daughters (Rahm, 2020).

- Studies of the ABAD programme find that CCTs for marriage postponement do not necessarily have long-term impacts on social norms and attitudes within the community, with little to no impact on larger social behaviours (Nanda et al., 2016; Krishnan et al., 2014).

\section{Empowerment of girls:}

- Improvements in the education of girls through educational stipend programmes have the potential to translate into gains in future productivity, inter-generational human capital accumulation and desired fertility (Hahn et al., 2018; Alam et al., 2011). 
- Research on the FSSSP indicate that an increase in female education through such stipend programmes can improve family planning, raise the socioeconomic status of women, and enhance gender equality in the long term (Hahn et al., 2018).

- An evaluation of the Save the Children programme also finds that financial incentives to delay marriage, and their positive impact on school enrolment, can improve the socioeconomic status of beneficiaries, allowing them to negotiate continued studies and further delays in marriage (Field et al., 2018).

- Similarly, a study of the FSSP finds that women with middle and high school education are likely to have fewer children and to invest more in their human capital and future productivity (Alam et al, 2011, 1).

- Where programmes delay marriage until the age of 18 , when terminal payments are made, it is uncertain what such a delay means for girls' well-being and empowerment over the long term (Nanda et al., 2016).

- Programmes based exclusively on financial incentives keep the focus on parents as decision-makers. (Amin et al., 2017). Girls married at 18 are largely still unable to plan their futures and make important life decisions on their own (Nanda et al., 2016).

\section{Unintended consequences of programmes}

- Higher fertility: Policies that aim to lower the sex ratio by incentivizing parents to have more girls may lead to higher fertility if parents respond by increasing the number of daughters without decreasing the number of sons equally (Anukriti, 2016).

- Worsening sex-ratio at birth: Incentives to lower fertility can translate into a more male-biased sex ratio in the case of persistent son preference (Anukriti, 2014). Higher financial incentives for parents to have only one girl, offered in the Devi Rupak scheme, have been unable to alter the behaviour of families with high son preference, inadvertently increasing the malebiased sex ratio at birth (Anukriti, 2016; Kumar \& Sinha, 2018).

- Female infanticide: Research on the Janani Suraksha Yojna programme in India, which aims to counter sex selection, finds that while it led to an increase in the number of girls being born, it also led to an increase in infant mortality among girls (Javadekar \& Saxena, 2019). In addition, efforts aimed at countering child marriage may have an unintended substitution effect, increasing the propensity for infanticide or abortion (Suarez, 2018).

- Mismatch of target group: Many CCTs target poor and socially excluded families among whom sex ratios are close to normal, rather than better off families among whom the practice of sex selection is pervasive (Rahm, 2020; Jejeebhoy et al., 2015). It may be questionable though to offer financial incentives to wealthy families (Rahm, 2020; Krishnan et al., 2014).

- Higher degree of marriage at age 18: CCTs have had the unintended effect of increasing the degree of marriage in the $18^{\text {th }}$ year, with some parents enrolling in programmes solely to help defray the cost of their daughter's marriage (Nanda et al., 2016; Amin et al., 2017). A study on ABAD finds that the proportion of girls marrying during their 18th year was higher for beneficiaries (59 percent) than for non-beneficiaries (45 percent) (Nanda et al., 2014, 5).

- Leaving boys behind: Educational CCTs targeted to girls could create disincentives to send boys to school as compared with girls (Sekhar and Ram, 2015; (Alam et al., 2011).

- School repetition and supply constraints: Families may try to keep their daughters in grades that make them eligible for cash transfers (Alam et al., 2011). Supply constraints can produce overcrowding, with increased demand for schooling due to CCTs (Alam et al., 2011). 


\section{Background}

Differences in the care of sons and daughters in South Asia stem from the perception of sons as assets and daughters as liabilities (Krishnan et al., 2014). Expected returns of investing in sons are considered higher as males tend to earn higher wages in the labour market and female labour participation is low. In addition, the practices of dowry and exogamous marriage reduce the expectation of girls' contributions to their natal homes (Krishnan et al., 2014).

In contexts where parents strongly prefer sons to daughters, parents may seek to deal with unwanted daughters through child marriage, infanticide, or sex-selective abortion (Suarez, 2018). Several papers document male-skewed sex ratio at birth, particularly in Asia (Kim, 2020). In the case of child marriage, laws on age of marriage have often been ineffective in stemming early marriage. In Bangladesh, for example, 59 percent of women between ages 20-24 were married before 18, despite the legal age of marriage being 18 (Field et al., 2018, 1). Child marriage reflects a lack of agency of adolescent girls in making important life choices (Amin et al., 2017). Early marriage is highly correlated with limited education and access to resources for women, and poor health outcomes for young women and their children (Field et al., 2018). Younger girls also tend to be married to significantly old men, which can undermine the agency and decisionmaking power of the adolescent girl in marriage. This, in turn, can lower reproductive control, or capacity to negotiate sexual relations, contraception and childbearing (Field et al., 2018).

Cash transfer schemes use monetary payments to provide short-term income support and to incentivize behavioural changes among parents and communities (Endow et al., 2015; Sekher, 2015). The aim of such initiatives is to ensure the survival and well-being of girls in the long run (Sekher, 2015). In India, several states have introduced financial incentive programmes to discourage son preference among parents by subsidising the costs of daughters (Kumar and Sinha, 2018; Krishnan et al., 2014). By compensating parents, the schemes seek to alter the (economic) value attributed to girls (Rahm, 2020). Many of the conditional cash transfers (CCT) are aimed at the poorest households (Sekher and Ram, 2015).

While many schemes emerged as a governmental reaction to address the highly skewed child sex ratio in various states in India, CCTs have much larger objectives and implications: to ensure educational opportunities for girls and delays in their age at marriage (Kumar and Sinha, 2018; Sekher and Ram, 2015; Krishnan et al., 2014). Direct financial support for girls, with funds often being transferred to a bank account in the name of the girl child, is considered a useful mechanism to promote investment in girls (Sekher, 2015).

Sex selection: Efforts to counter sex-selection include three main approaches: (1) advocacy and media outreach to encourage parents to perceive girls to be as valuable as boys; (2) financial incentives for parents to raise daughters; and (3) bans on the use of technology for sex-selective abortion for non-medical purposes (Guo et al., 2016). Financial incentives represent a shift in the approach of how the government addresses sex selection away from policy instruments that ban methods of sex selection towards a more motive-driven approach (Rahm, 2020).

Child marriage: Efforts to counter child marriage include: (1) minimum marriage-age laws; (2) CCTs that provide a monetary or in-kind reward to a couple if their daughter reaches a predetermined age as a single female or to a young female herself if she remains unmarried by this age; and (3) educational programmes that inform parents, young females and males about the poor socio-economic outcomes for females linked to early female marriage (Suarez, 2018). 
Education: Low enrolment of girls in schools is often compounded by low retention and completion rates (Alam et al., 2011). Most schemes in South Asia and elsewhere that seek to promote school education for girls provide scholarships and stipends to reduce the gender imbalance in schools (Sekher \& Ram, 2015).

Some cash transfer schemes offer the entire incentive when the girl turns 18 years, whereas others stagger the incentives over the years, particularly during the schooling years (Endow et al., 2015). Such staggered financial incentives can improve the retention of beneficiary girls in school, enabling them to continue their education and overcome social pressures such as early marriage (Endow et al., 2015).

Given that many CCT programmes aimed at addressing girl children are relatively new, it is in many cases too early to evaluate the effectiveness of the programmes. As such, there is limited evidence of the impact of their implementation and outcomes (Sekher \& Ram, 2015). In addition, evaluation and monitoring systems are often weak across many cash incentive schemes in support of the girl child, which undermines the collection of baseline data necessary in order to track the effectiveness of the programmes and impact on beneficiaries over time (Endow et al., 2015).

\section{Programme design}

\section{India}

Apni Beti Apna Dhan (ABAD) ('Our Daughter, Our Wealth') is a CCT programme (1994-1998) developed by the Government of Haryana in India, aimed at enhancing the value of girls. Beneficiaries faced a protracted 18-year wait before receiving any cash transfer (Krishnan et al., 2014; Nanda et al., 2014; Sinha \& Yoong, 2009). There are two points of transfer: 1) a small cash disbursement to mothers (500 Indian Rupees) within 15 days of delivering an eligible girl; and 2) within three months of birth, and upon enrolment in the programme, the government purchased a savings bond of Rs.2500 in the name of the daughter that is redeemable at a maturity of 25,000 Indian Rupees at age 18, if the girl was not married (Nanda et al., 2014).

ABAD targeted poor households and disadvantaged caste groups (Sinha and Yoong, 2009). The scheme was replicated in other states, and was later replaced by the 'Laadli' scheme in 2005, which restricted the benefit to the second girl child, removed restrictions about being disadvantaged, and increased the incentive at maturity (Krishnan et al., 2014).

The Dhanalakshmi Scheme is a CCT programme for girls, introduced in 2008 and supported by the Government of India. It provides a set of staggered financial incentives for families in seven states in India to encourage them to retain and educate a girl child, and to prevent child marriage. Cash transfers are made to the family at the birth of a girl and when the girl fulfils certain specific conditions, such as birth registration, immunisation, school enrolment and retention up to Class 8, and delay in marriage till the age of 18 (Jejeebhoy et al., 2015; Sekher \& Ram, 2015). Parents enrolled their daughters in the scheme primarily to meet their educational and marriage expenses (Sekher \& Ram, 2015). The programme also aims at a gradual change in the attitude and mindset of the family towards the girl by linking cash (and non-cash transfers) to her well-being and fostering the view of the girl child as an asset, linked to cash inflows into the household (Sekher \& Ram, 2015). 
Devi Rupak is a CCT programme initiated in 2002 by the Indian state of Haryana, with the dual aim of reducing fertility and balancing the sex ratio at birth in the state (Anukriti, 2016). In addition to rewarding one-child parents, it also rewards couples that have two daughters and no sons. The incentive amount varies with the number and the sex composition of their children at the time of sterilization. Registered couples receive the benefits only after the surgical procedure has taken place. Payments are disbursed on a monthly basis for a period of 20 years. Their magnitude is substantial, with the total benefit received over 20 years amounting to enough funds to cover the average dowry expense (Anukriti, 2016).

Janani Suraksha Yojna is a CCT programme, launched by the Government of India in 2005 to influence household decisions on the gender composition of their children, with the aim of reducing maternal and neonatal mortality rates (Javadekar and Saxena, 2019). It provides access to prenatal sex determination technology, through a precondition of undertaking at least three antenatal checks, and reduces the cost of childbearing through a cash transfer on a live birth in a health institution (Javadekar and Saxena, 2019).

\section{Bangladesh}

The Female Secondary School Stipend Programme (FSSSP) was introduced in Bangladesh in 1994, with the objective of increasing female enrolment and retention rates in secondary school through the provision of cash stipends and reduction of tuition fees for girls. It also aims to enhance female employment opportunities; and to delay the age at which girls married (Hahn et al., 2018). In order to receive the stipend, a girl needed to satisfy three conditions: 1) a minimum of 75 percent attendance rate in school; 2) at least a 45 percent test score in annual school exams; and 3) remaining unmarried until age 18 (Hahn et al., 2018). The stipend varied between ages and grades (Hahn et al., 2018). The programme was later changed to also include stipends for poor boys (Field et al., 2018).

Save the children (SC)'s girls' empowerment programme, which was implemented in five subdistricts, in three coastal districts, in the south central region of Bangladesh, had two main parts: the Kishora Kontha (KK) programme and the conditional stipend programme (Field et al., 2018). The KK programme consisted of two interventions for girls 10-19 years old, made up of three components: community mobilization, education and social competency (Field et al., 2018). The conditional stipend programme built on the FSSSP, with a few changes. The FSSSP did not reach out-of-school girls and did not provide any outside help to ensure girls met the conditions for receiving the stipend; whereas in the KK programme area, many girls were both out of school and unmarried (Field et al., 2018).

An in-kind transfer, in the form of oil incentives (with high monetary value) delivered to girls three times a year, was designed to encourage parents not to marry their adolescent daughters before the legal age of consent (Field et al., 2018). Girls aged 15, 16 and 17 at the time of oil distribution start and confirmed to be unmarried by hired staff, were issued ration cards to collect the stipend for the first year of the programme (Field et al., 2018). The interventions were composed of the two KK interventions and the oil incentive in different combinations.

\section{Pakistan}

The Punjab Female School Stipend Programme (FSSP), a targeted CCT programme in Pakistan, was implemented in response to gender gaps in education (Alam et al., 2011). For families with daughters out of middle school, the programme's condition on school attendance 
induces a substitution effect since it reduces the price of education (Alam et al., 2011). For families that would have sent their daughters to middle school with or without the programme, the programme has an income effect (Alam et al., 2011). Both effects point toward an increase in the demand for education, particularly among poorer households in environments with imperfect capital markets. Higher demand for and utilisation of education services is expected to lead to higher school progression and completion over time (Alam et al., 2011).

\section{Programme outcomes - short and medium-term}

There is evidence to suggest that CCT programmes aimed at supporting the girl child have succeeded in promoting birth registration, immunisation, school enrolment and delayed marriage in India (and elsewhere) (Jejeebhoy et al., 2015). It is less clear, however, the extent to which these transfers have induced parents to stop engaging in gender-biased sex selection (Rahm, 2020; Jejeebhoy et al., 2015).

\section{Sex selection}

An evaluation of ABAD finds that improvements in the survival rate of girl children during 19932006 was higher among those eligible for the ABAD programme (Krishnan et al., 2014). This positive effect is observed in improvements in the sex ratio of mother's total living children over time (Sinha and Yoong, 2009). A study of the Devi Rupak programme, which seeks to lower fertility and the sex ratio, finds instead that financial incentives may play only a limited role in the resolution of the fertility-sex ratio as the demand for sons is less 'price-elastic' than the demand for daughters (Anukriti, 2016). While fertility declines, the sex ratio at birth worsens as high son preference families are unwilling to forgo a son despite significantly higher benefits for a daughter (Anukriti, 2016). Recent research conducted by the Population Council on the grassroots effects of interventions against sex selection, including CCTs in two districts of Haryana finds that there were no strong signs that CCTs reduce sex-selective behaviour (see Rahm, 2020).

In South Korea, pro-natalist cash transfers to counter rapidly declining fertility have increased birth rates and modulated the son preference (Kim, 2020). Research indicates that such cash transfers interact with son preference and unintentionally alleviate sex ratio imbalance in a cultural context where having sons is favoured over having daughters (Kim, 2020).

\section{Child marriage}

Survey findings indicate that the Dhanlakshmi scheme was effective in altering parents' preferences toward delaying marriages (Sekhar \& Ram, 2015). One of the conditions to receive the terminal benefit is that the daughter remains unmarried until the age of 18 . Seventy-eight percent of beneficiary parents stated that even if they were to get a good marriage proposal for their daughter, they would not arrange her marriage until after she is 18 (Sekher \& Ram, 2015, 95). The age at marriage may increase not only due to specific marriage conditionality, but also because the scheme mandates the continuation of girls' education up to a certain level, which indirectly delays their marriage (Sekher \& Ram, 2015).

In contrast, an evaluation of the ABAD programme, conducted by the ICRW, finds that participation in the programme had no effect on the probability of being currently married or on the probability of marriage before age 18 (Nanda et al., 2016). While there was a lower proportion of beneficiary girls married (13.3 percent) compared to non-beneficiaries (17.1 
percent), the possible benefit of the programme did not persist when the study accounted for self-selection and other factors at the individual, household and village levels. (Nanda et al., $2016,5)$. The absence of a programme effect is reflective of an overall trend toward later age of marriage in the state of Haryana, where the programme was implemented (Nanda et al., 2016). The evaluation also suggests, however, that while the ABAD programme enabled beneficiary households to delay girls' marriage to age 18 , it was unable to shift the attitudes and aspirations of girls and their mothers in favour of further delaying age of marriage and toward gender equality (Nanda et al., 2016).

In Bangladesh, research on the FSSSP finds that the programme had large effects on age of marriage and on education (see Field et al., 2018). An earlier study finds that the FSSSP contributed to raising the age of marriage of women by 1.4 to 2.3 years, with some evidence that the age of marriage of men has also gone up (Hong \& Sarr, 2012,1). A more recent study finds that the FSSSP delays age at first marriage by 0.57 years ( 3.6 percent) or on average 0.11 years for each year of exposure for those in beneficiaries, who received the stipend for 5 years (Hahn et al., 2018, 400). For girls who received the stipend for 2 years, exposure to the FSSSP increases age at first marriage by 0.34 years $(2.1 \%)$, or 0.17 years for each year of exposure (Hahn et al., 2018, 400). The effect on age at first birth is slightly lower but is similar to the effect on age at first marriage, indicating that delayed first birth is likely due to delayed marriage rather than to delayed birth after getting married (Hahn et al., 2018, 400).

An evaluation of the Save the Children scheme in Bangladesh finds that a relatively inexpensive conditional stipend programme targeted to the families of adolescent girls can delay the marriage of participants - and is more effective than minimum age requirements and dowry prohibitions (Field et al., 2018). The financial incentive reduced the likelihood of being married under age 18 by 22 percent (Field et al., 2018, i). For girls aged 15 at the programme start, the likelihood of being married under age 16 fell by 23 percent in the incentive only group and 29 percent in the group that received the incentive and empowerment training (Field et al., 2018, i). Regression analysis indicates that the financial incentive on its own increased marriage age an average of 5.2 months (Field et al., 2018, 26). In terms of cost-efficacy, the study finds that the financial incentive translates into 1.62 years of delayed marriage and 1.00 years of schooling for every US $\$ 1,000$ invested (Field et al., 2018, 50). There is further evidence suggesting that the reduction in child marriage has a substantial positive impact on girls' schooling attainment (Field et al., 2018).

The study also finds, however, similar to the ABAD programme, that while the financial incentive delayed marriage, it did not prevent it. The distribution of marriage ages, analysed 4.5 years following programme completion, suggests that while fewer marriages took place between ages 14 and 17.5 (programme beneficiary ages), more took place between ages 18 and 20 compared to the control group (Field et al., 2018, 50).

\section{Education}

Just as financial incentives provided to stem child marriage can influence education outcomes, CCTs targeting the education of girls can influence age of marriage. Evidence from various parts of the world suggest that ensuring schooling for girls is an effective pathway to delay their marriage (Sekher \& Ram, 2015). Evaluation studies find that parents respond positively to financial incentives for enrolling their children in school, particularly girls - and that CCTs have reduced the gender imbalance in enrolment and retention of girls in schools. Adolescent girls, 
who received scholarships, for example, increased their schooling more than the adolescent boys who had no scholarships (Sekher \& Ram, 2015).

More than half of the respondents from Andhra Pradesh, Odisha and Punjab reported that the Dhanlakshmi scheme has brought about changes in better education for girls (Sekher \& Ram, 2015). Being a Dhanlakshmi scheme beneficiary increased the probability of being in school by 10 percent and parental intention of educating their daughters past tenth standard by 13 percent (in comparison to non-beneficiaries) (Sekher \& Ram, 2015, 89). Over 40 percent of respondents in Andhra Pradesh and Punjab felt that the programme also improved care for girls. (Sekher \& Ram, 2015, 86).

While the evaluation of the ABAD programme finds no direct effect on child marriage, its companion study finds that a CCT programme designed to delay the age of marriage can improve educational outcomes for girls (Nanda et al., 2014). ABAD beneficiaries are 23 percent more likely to be in school after age 15 than non-beneficiaries (Nanda et al., 2014, 7).

Beneficiaries were more likely to continue their education and less likely to drop out than nonbeneficiary girls (Nanda et al., 2014). While families may not necessarily have claimed the cash benefit of the CCT, their knowledge of the protracted benefit was enough to influence their decision to invest in their daughters' education (Nanda et al., 2014). The study also suggests, in turn, that education plays an important role in the trend toward later age of marriage (Nanda et al., 2016). Beneficiary girls were 12 percent more likely to complete 8th grade and 19 percent more likely to aspire to study beyond 12th grade (Nanda et al., 2016, 6). These factors may have had a strong influence on their delayed marriage beyond 18 (Nanda et al., 2016).

There is also evidence in the case of Bangladesh that the FSSSP increased the likelihood of eligible women completing secondary school or beyond, with the marked increase in enrolment among girls since the introduction of the FSSSP exceeding the number of boys (Hahn et al., 2018). The study finds that exposure to the stipend programme increased the years of schooling for female students by 0.6 to 1.2 years and that girls exposed to the programme married later and had lower desired and actual fertility (Hahn et al., 2018, 410). A prior study of the FSSSP finds that it contributed to raising women's years of education by 1.6 to 2 years, while the free tuition policy did not have any significant impact on their educational attainment (Hong \& Sarr, $2012,1)$. As noted, the stipend programme also led to an increase in the age of marriage of women (Hong \& Sarr, 2012).

These changes have not only narrowed the gender gap in secondary school enrolment in Bangladesh, but also reversed it (Hong \& Sarr, 2012). According to the Bangladesh Bureau of Educational Information and Statistics, the male to female student ratio at the secondary level was 66:34 in 1990, changing to 46:54 by 2012 (Hahn et al., 2018, 389). Such an increase in female education can have a significant impact on improving family planning and enhancing gender equality in developing countries (Hahn et al., 2018).

An early evaluation of Punjab School Stipend Programme in Pakistan indicates that the enrolment of eligible girls in middle school increased by nearly 9 percentage points (Alam et al., 2011). Beneficiary adolescent girls are also more likely to complete middle school. The 12-17 year-old girls who were exposed to the programme between 2003-04 and 2007-08 are on average around 3.3 percentage points more likely to have completed middle school (grade 8) relative to the control cohorts (Alam et al., 2011, 19). The impacts on middle school completion are largest for girls aged $15-16$ at 6 percentage points more likely to have completed middle school (Alam et al., 2011, 19). Girls who were later eligible for the benefits given in high school 
also increase their rates of matriculating into and completing high school (Alam et al., 2011). These impacts have the potential to translate into gains in future productivity, inter-generational human capital accumulation and desired fertility (Alam et al, 2011). There is evidence that participating girls delay their marriage by 1.4 years and have fewer births by the time they are 19 years of age (Alam et al., 2011; see Sekhar \& Ram, 2015, 19).

\section{Programme outcomes - longer-term equality}

\section{Greater value given to girls, changes in attitudes and treatment of girls}

While there are indications that CCTs are making girls much more valuable, there are mixed views and findings on the efficacy of financial incentives as a long-term strategy (Rahm, 2020). In the absence of ongoing government attention, there is the risk that once incentives are removed, economic insecurities and traditional perspectives will prevail and families are likely to resort to the default position of valuing sons over daughters (Rahm, 2020).

A study examining the impact of CCT programmes on parents' attitude and behaviour towards girl children finds that financial incentives can play an enabling role in removing the gender barriers and altering parental perception of daughters as a 'liability' (Sekher \& Ram, 2015). Household survey data from the Dhanlakshmi scheme, for example, indicates that most families felt 'less burdened' to have girls with the receipt of financial support for their education and marriage (Sekher \& Ram, 2015). This is likely one of the reasons for girls being treated and valued better in beneficiary households than in non-beneficiary families in the villages studied (Sekher \& Ram, 2015).

Research on the Dhanlakshmi scheme also finds that people in the villages in which it was implemented perceive the scheme as effective in the changing attitudes and practices of families towards daughters (Sekher \& Ram, 2015). The views expressed by parents illustrate that better education and better care for girls are visible in villages (Sekhar \& Ram, 2015). Ninety percent of the beneficiary families interviewed believed that the scheme will help in securing their daughter's future; and 87 percent of the beneficiary parents stated that they now give equal treatment for their sons and daughters within the households (Sekher \& Ram, 2015, 95). Even after controlling for other characteristics, beneficiary households in the study are more positively inclined towards gender equality than non-beneficiary families, including in relation to marriage and education (Sekher \& Ram, 2015). The scheme has thus contributed to the development of favourable attitudes toward girls among parents, galvanising the process of attitudinal change at family and community levels (Sekher \& Ram, 2015). In the case of education, a study of the

ABAD programme, finds that once girls attend any school, they may be more likely to continue their education (Sinha \& Yoong, 2009).

A more recent study of the ABAD programme finds, however, that CCTs for marriage postponement do not necessarily have long-term impacts on social norms and attitudes within the community (Nanda et al., 2016). This is supported by another study on ABAD, which finds that they tend to have little to no impact on addressing larger social behaviours and on changing societal mindsets (Krishnan et al., 2014). There is no evidence that the Dhanlakshmi and ABAD programmes changed families' preference for girl children (Sekhar \& Ram, 2015; see Kumar \& Sinha, 2018). In addition, parents often saw the terminal benefits of the schemes as a means to meet the marriage costs of their daughters (Sekher \& Ram, 2015). 
Giving out cash on its own is thus unlikely to address social issues and to achieve transformational changes in the lives of girl children (Endow et al., 2015; Krishnan et al., 2014). They need to be part of a larger social protection system and supplemented by effective provision of quality services (Nanda et al., 2016; Endow et al., 2015; Krishnan et al., 2014). Longer-term societal and attitudinal changes should also be directly targeted in CCT programmes, such as with empowerment programmes that involve the community and adolescents in implementation (Nanda et al., 2016; Endow et al, 2015; Krishnan et al., 2014).

\section{Empowerment of girls}

A study of the FSSSP in Bangladesh finds that in addition to the stipend programme contributing to a raise in age of marriage and in women's years of education (discussed above), each additional year of education leads to a 2.4 to 5.3 percent increase in the labour force participation of married women (Hong \& Sarr, 2012, 1). Findings from another study of the FSSSP also indicate that an increase in female education through such stipends can have a significant impact on improving family planning and enhancing gender equality in the long term (Hahn et al., 2018). In addition to greater years of schooling for female students, girls exposed to the programme married later, had lower desired and actual fertility, and were more likely to work in the formal sector than in the informal sector or in agriculture (Hahn et al., 2018). Stipendeligible women also married more educated husbands who had a better occupation and who were more similar in age (Hahn et al., 2018). Results from the study suggest that the stipend programme can improve the socioeconomic status of women later in life, in a setting with initial low levels of education and high prevalence of early marriage (Hahn et al., 2018).

An evaluation of the Save the Children programme in Bangladesh also finds that the financial incentive to delay marriage under the programme and the positive impact this has on school enrolment can improve the socioeconomic status of beneficiaries (Field et al., 2018). An older and more educated girl may be better able to negotiate continuation of her education or further delay her marriage (Field et al., 2018). The financial incentive also reduces the likelihood of the beneficiary having given birth by the end of the programme and increases the age of first birth amongst married girls by 2.6 months. There is evidence of stronger reproductive outcomes for younger girls (aged 15 at programme start) if they received both the financial incentive and empowerment training. There is, however, no separate or additional effect of the empowerment programme on its own (Field et al., 2018, I, 28).

A study of the FSSP in Pakistan finds that women in Punjab with middle and high school education are likely to have fewer children and to invest more in their human capital and future productivity, which may lead to positive intergenerational effects (Alam et al, 2011, 1). For instance, women in Punjab that complete middle and high school live in households that have up to 30 percent higher consumption per capita than women with less than middle school education (Alam et al., 2011). This may be because higher education may enable Pakistani women to increase their earnings; or because educated women are more likely to marry men who have also have more education than women with less education (Alam et al., 2011, 1).

Potential positive intergenerational effects of successful CCT programmes are also indicated in research on the FSSSP in Bangladesh. The children of eligible women of the programme, who received greater education and married later, were taller and heavier for their age, suggesting that the stipend generated positive intergenerational health effects (Hahn et al., 2018). In contrast, here can be strong correlations between child marriage and long term outcomes for girls and their children such as poor education and health risks (Field et al, 2018). 
Where programmes are able to contribute to delays in the age of marriage until 18 years, when terminal payments are made, it is uncertain what such a delay means for girls' well-being and empowerment over the long term (Nanda et al., 2016). Girls married at 18 (or any age) are largely still unable to plan their futures and make important life decisions on their own (Nanda et al., 2016). Programmes based exclusively on financial incentives keep the focus on parents as decision-makers, without explicit efforts to improve the agency of adolescent girls (Amin et al., 2017). Parents respond to financial incentives, but this is unlikely to translate into wider social change, including change in the agency of the girl herself (Amin et al., 2017).

A study on the ABAD programme finds that while girls' aspirations and their educational attainment were important and significant mechanisms of change, they were not strong enough to push the age of marriage beyond the age of 18. Programme beneficiaries were more likely to marry during their $18^{\text {th }}$ year than non-beneficiaries (Amin et al, 2017; Nanda et al., 2016).

Qualitative data indicates that marriage is still prioritised in Haryana over other aspects of a girl's future, such as higher education or employability (Nanda et al., 2016). Further, families primarily see girls' education as valuable for enhancing their marriageability, rather than as a pathway to new opportunities and to socially acceptable alternatives to marriage (Nanda et al., 2016).

\section{Unintended consequences of programmes}

\section{Higher fertility}

Policies that aim to lower the sex ratio at birth by incentivizing parents to have more girls or by improving the relative value of girls may lead to higher fertility if parents respond by increasing the number of daughters without decreasing the number of sons equally (Anukriti, 2016). This may occur if parents do not see sons and daughters as perfect substitutes or if parents desire a minimum number of sons (Anukriti, 2016). For example, an increase in the relative labour market returns of females among low socioeconomic status groups in India lowered the sex ratio at birth and relative female child mortality, but increased fertility (Anukriti \& Kumler, 2014; cited in Anukriti, 2016). Fertility reduction and a gender-balanced population can thus be conflicting objectives, with efforts to target one producing negative effects on the other (Anukriti, 2016). Further, research on the Devirupak programme in India finds that the larger financial incentives per child offered to one-child couples (relative those who have two or more children) unintentionally incentivises couples to have at least one child, since childless couples receive nothing. This runs contrary to the scheme's aim of decreasing fertility (Anukriti, 2014).

\section{Worsening sex-ratio at birth}

Decisions about fertility and sex selection depend not only on the cost of children, but also on the degree of son preference (Anukriti, 2014). Financial incentives have not been able to achieve the dual aims of both decreasing fertility and modifying the sex ratio at birth (Anukriti, 2014). A study on Devi Rupak, a programme which seeks to decrease both fertility and the sex ratio, finds that the programme has had the unintended consequence of increasing the male-biased sex ratio at birth, alongside the reduction in fertility (Anukriti, 2016; Kumar \& Sinha, 2018). Families responded to financial incentives to have only one boy to reduce fertility, forgoing unwanted daughters (Anukriti, 2016). The decline in the number of living children by 1 percent is driven primarily by a 2 percent decline in the number of living girls (Anukriti, 2014, 3). The higher financial incentives for having only one girl have not been able to alter the behaviour of families with high son preference, who are unwilling to forgo a son (Anukriti, 2016). Targeting socio- 
economic groups that have historically exhibited a stronger preference for sons may be more successful in modifying the sex ratio at birth (Anukriti, 2014). In addition, removing the one-boy option from the programme, could avoid the increase in the sex ratio at first birth, but may then adversely affect the fertility decline (Anukriti, 2016).

Research on the ABAD scheme in Haryana similarly recommends that removing the financial benefits for the one-boy only families may be a way to balance the sex ratio at birth and thus to improve the short-term effectiveness of the programme (Kumar \& Sinha, 2018). However, research also indicates that programmes that do not provide benefits for male children still show mixed results in lowering son preference (Kumar \& Sinha, 2018).

Differing results are found in evaluations of the pro-natalist cash transfer programmes in South Korea. Here, financial incentives aimed at increasing fertility had the unintended consequence of modulating son reference and decreasing the sex ratio imbalance favouring boys toward the natural sex ratio at birth (Kim, 2020). In particular, the transfers decreased the probability of a third child being a boy. It is estimated that the sex ratio among third children born in 2015 would have been 114.3 boys per 100 girls in the absence of the cash transfers, in contrast to the natural sex ratio at birth of 105 boys for 100 girls (Kim, 2020, p. 3).

\section{Female infanticide}

Research on the Janani Suraksha Yojna programme in India, which aims to counter sex selection, finds that while it led to an increase in the number of girls being born (at each birth order), it also led to an increase in infant mortality among girls, specifically at higher birth orders (Javadekar \& Saxena, 2019). The programme provided access to prenatal sex determination technology, through a precondition of undertaking at least three antenatal checks, and aimed to reduce the cost of childbearing through a cash transfer on a live birth in a health institution (Javadekar \& Saxena, 2019). The programme unintentionally influenced the sex selective behaviour among Indian parents, effectively shifting gender discrimination from pre-natal to postnatal stages. The study also finds that among the surviving children, girls on average have lower nutritional status than boys their age (Javadekar \& Saxena, 2019).

Efforts aimed at countering child marriage, such as minimum marriage-age laws, CCTs, and educational programmes, may have an unintended substitution effect, increasing the propensity for infanticide or abortion (Suarez, 2018). By raising parents' cost of disposing of their unwanted daughters through child marriage, parents may now choose to do so via infanticide or abortion (Suarez, 2018). This unintended effect is attributable to the persistence of son preference, which remains unaffected by policies and incentives to counter child marriage (Suarez, 2018).

Research on the ABAD scheme, for example, finds that the difference between eligible and noneligible females' sex ratio at birth increases by 0.227 males per female $4-5$ years after ABAD's implementation and by 0.434 males per female 12 years after ABAD's implementation (Suarez, $2018,17)$. This is consistent with the prediction that policies aimed at raising female marriage age in son-preferring societies may result in higher prevalence of sex-selective abortion and female infanticide. Further, the extent to which ABAD induces son-preferring couples to substitute female infanticide and sex-selective abortion as means of unwanted daughter disposal increases with the degree of son preference (Suarez, 2018). 


\section{Mismatch of target group}

There is often a mismatch in the purpose and target of schemes aimed at deterring genderbased sex selection (Rahm, 2020; Jejeebhoy et al., 2015). Many target poor and socially excluded families among whom sex ratios are close to normal, rather than better-off middle and upper class families among whom the practice of gender-biased sex selection is most pervasive (Rahm, 2020; Jejeebhoy et al., 2015). At the same time, it may be questionable to focus on financial incentives in relation to a social problem which is more common among the rich and educated. The quantum of benefit will likely be too little for these groups to have any interest and, in turn, to effect any kind of behaviour change (Rahm, 2020; Krishnan et al., 2014).

\section{Higher degree of marriage at age 18}

While CCTs aimed at countering child marriage have been effective in postponing the age of marriage of girls, they may have the unintended effect of increasing the degree of marriage in the $18^{\text {th }}$ year. A study on $A B A D$, for example, finds that the proportion of girls marrying during their 18th year was higher for beneficiaries (59 percent) than for non-beneficiaries (45 percent) (Nanda et al., 2014, 5). The instrumental effect of the cash benefit was thus to motivate beneficiary parents to marry their daughters off upon receipt of the benefit (Nanda et al., 2016). Data on cash use supports this finding as participants both intended and actually used the cash incentive for marriage purposes, with over 50 percent of respondents who had cashed out reported using the funds for marriage expenses (Nanda et al., 2014, 5). This suggests that some parents enrolled in the programme solely to help defray the cost of their daughter's marriage (Nanda et al., 2016; Amin et al., 2017). Similarly, in Bangladesh, a study of Save the Children's programme finds that more marriages took place between ages 18 and 20, following the completion of the incentives, compared to the control (Field et al., 2018).

Providing the terminal benefit when the girl turns 18 needs to be reconsidered as it can create an impression that the government is providing the incentives in order to support the cost of marriage. Providing benefits after girls have completed various stages of education may a more effective way to delay marriage and to empower girls (Sekher and Ram, 2015).

\section{Leaving boys behind}

Educational CCTs that are targeted at girls can have indirect effects on households' investments in the education of ineligible siblings (Alam et al., 2011). The income effect of the transfers could enable budget-constrained households to send all children to school; whereas the displacement effect may incentivize parents to reallocate child work away from eligible girls toward boys and other ineligible girls (Alam et al., 2011). In the case of the FSSSP in Bangladesh, parents responded positively to the financial incentives for enrolling their children, particularly girls (Sekher \& Ram, 2015). Adolescent girls, who received scholarships, increased their schooling more than the adolescent boys without scholarships (Sekher \& Ram, 2015). Research finds that adolescent boys increased the amount of time that they spend on wage work, suggesting that the incentive schemes may have created disincentives to send boys to school as compared with girls (Sekhar \& Ram, 2015). In order to minimise any potential unintended negative impacts on boys within the households, it may be necessary to target children of both sexes in poorer households in scholarship schemes (Sekher \& Ram, 2015).

In contrast, in Pakistan, research on related programming does not reveal any spillover effects of the programme on the enrolment and school completion of boys (Alam et al., 2011). Enrolment 
and school completion rates of boys with female siblings who have been exposed to the FSSP exhibit statistically similar trends as boys with no eligible siblings in both stipend and non-stipend districts (Alam et al., 2011).

\section{School repetition and supply constraints}

Educational cash transfers can create perverse incentives or constraints that prevent programme beneficiaries from progressing and accumulating more human capital. In particular, families may try to keep their daughters in the particular grades that make them eligible for the transfers (Alam et al., 2011). Supply constraints can also produce overcrowding in schools due to the additional demand from education stemming from the programmes, such as the FSSSP in Bangladesh and the FSSP in Pakistan (Alam et al., 2011). Despite the success of the FSSSP, many children are still not in school, which may be due in part to inadequate supply of schools. This has not been addressed, however, in evaluation studies (Sekher \& Ram, 2015). 


\section{References}

Alam, A, Baez, J E \& Carpio, X.V.D (2011) Does cash for school influence young women's behaviour in the longer term? Evidence from Pakistan, Policy Research Working Paper: 5669, Independent Evaluation Group, Public Sector Unit, World Bank. http://ftp.iza.org/dp5703.pdf

Amin, S., Asadullah, M. N., Hossain, S. \& Wahhaj, Z. (2017). Cash transfers to end child marriage: The Indian experience. Ideas for India.

https://www.ideasforindia.in/topics/governance/cash-transfers-to-end-child-marriage-the-indianexperience.html

Anukriti, S. (2018). Financial incentives and the fertility-sex ratio trade-off. American Economic Journal: Applied Economics, 10(2), 27-57.

https://www.aeaweb.org/articles?id=10.1257/app.20150234

Endow, T., Sekher, T.V. \& Lahiri, A. (2015). Cash Transfers for Children: The Experience of Indian States. Discussion paper prepared for National Workshop on Cash Transfers for Children. New Delhi: United Nation Children's Fund. http://www.ihdindia.org/pdf/cashtransfer.pdf

Field E, Glennerster R, Nazneen S, Pimkina S, Sen I \& Buchmann N. (2018). Age at marriage, women's education, and mother and child outcomes in Bangladesh. New Delhi: International Initiative for Impact Evaluation (3ie). https://reliefweb.int/sites/reliefweb.int/files/resources/ie_68bangladesh-marriage.pdf

Guo, Z., Das Gupta, M., \& Li, S. (2016). 'Missing girls' in China and India: Trends and policy challenges. Asian Population Studies, 12(2), 135-155.

https://doi.org/10.1080/17441730.2016.1142795

Hahn, Y., Islam, A., Nuzhat, K., Smyth, R., \& Yang, H. S. (2018). Education, marriage, and fertility: Long-term evidence from a female stipend program in Bangladesh. Economic Development and Cultural Change, 66(2), 383-415. https://doi.org/10.1086/694930

Hong, S.Y. \& Sarr, L.R., (2012). Long-term Impacts of the Free Tuition and Female Stipend Programs on Education Attainment, Age of Marriage, and Married Women's Labour Market Participation in Bangladesh." World Bank Working Paper 81061. Washington, DC: the World Bank. https://documents.worldbank.org/en/publication/documents-

reports/documentdetail/442221468210891194/long-term-impacts-of-the-free-tuition-and-femalestipend-programs-on-education-attainment-age-of-marriage-and-married-womens-labor-marketparticipation-of-in-bangladesh

Javadekar, S., \& Saxena, K. (2019). The Impact of a Conditional Cash Transfer Program on Household's Fertility Choices in India. Available at SSRN 3341448.

https://papers.ssrn.com/sol3/papers.cfm?abstract_id=3341448

Jejeebhoy, S. J., Acharya, R., Basu, S. and Zavier, A.J. F. (2015). Addressing gender-biased sex selection in Haryana, India: Promising approaches. New Delhi: Population Council.

https://knowledgecommons.popcouncil.org/cgi/viewcontent.cgi?article=1646\&context=departmen ts_sbsr-pgy

Kim, W. (2020). Baby Bonus, Fertility, and Missing Women. Fertility, and Missing Women (October 21, 2020). https://papers.ssrn.com/sol3/papers.cfm?abstract_id=3704188 
Krishnan, A., Amarchand, R., Byass, P., Pandav, C., \& Ng, N. (2014). "No one says 'No'to money"-a mixed methods approach for evaluating conditional cash transfer schemes to improve girl children's status in Haryana, India. International journal for equity in health, 13(1), 11. https://link.springer.com/article/10.1186/1475-9276-13-11

Kumar, S., \& Sinha, N. (2018). Preventing more 'Missing Girls'. Washington, DC: World Bank. https://openknowledge.worldbank.org/bitstream/handle/10986/30656/WPS8635.pdf?sequence=1 \&isAllowed $=y$

Nanda, P., Datta, N., Das, P., Lamba, S., Kumar, S., Rouhani, S., ... \& Verma, R. (2016). Making change with cash? Impact of a conditional cash transfer program on age of marriage in India. New Delhi: International Centre for Research on Women. https://www.icrw.org/publications/making-change-with-cash-impact-of-a-conditional-cashtransfer-program-on-age-of-marriage-in-india/

Nanda, P., Datta, N., \& Das, P. (2014). Impact of conditional cash transfers on girls' education, IMPACCT-Summary of Research Findings. New Delhi: International Centre for Research on Women. https://www.icrw.org/wp-content/uploads/2016/10/IMPACCT_Hires_FINAL_3_20.pdf

Rahm, L. (2019). Gender-Biased Sex Selection in South Korea, India and Vietnam: Assessing the influence of public policy. Springer International Publishing

Sekher, T. V., \& Ram, F. (2015). Conditional cash transfers for girls in India: Assessment of a girl child promotion scheme from beneficiary perspective. International Institute for Population Sciences. https://www.iipsindia.ac.in/sites/default/files/lips-Report-CT-Girls-in-India.pdf

Sekher, T. V. (2015). Conditional Cash Transfers for the Welfare of the Girl Child: The Indian Experience. Chapter 12: (p.307) India's Children: Essays on Social Policy A. K. Shiva Kumar, Preet Rustagi, and Ramya Subrahmanian. Oxford University Press.

https://oxford.universitypressscholarship.com/view/10.1093/acprof:oso/9780199455287.001.000 1/acprof-9780199455287-chapter-12?print=pdf

Sinha, N., \& Yoong, J. (2009). Long-term financial incentives and investment in daughters: Evidence from conditional cash transfers in north India. Washington DC: World Bank. Policy Research Working Paper \#4860. Washington, DC: World Bank. https://elibrary.worldbank.org/doi/abs/10.1596/1813-9450-4860

Suarez, P. A. (2018). Child-bride marriage and female welfare. European Journal of Law and Economics, 45(1), 1-28. https://link.springer.com/article/10.1007/s10657-017-9562-7 


\section{Acknowledgements}

- Laura Rahm (University of Barcelona)

- T.V. Sekher (International Institute for Population Sciences)

\section{Suggested citation}

Haider, H. (2020). Financial incentives to reduce female infanticide, child marriage and to promote girls' education. K4D Helpdesk Report 943. Brighton, UK: Institute of Development Studies. DOI: 10.19088/K4D.2021.004

\section{About this report}

This report is based on six days of desk-based research. The K4D research helpdesk provides rapid syntheses of a selection of recent relevant literature and international expert thinking in response to specific questions relating to international development. For any enquiries, contact helpdesk@k4d.info.

K4D services are provided by a consortium of leading organisations working in international development, led by the Institute of Development Studies (IDS), with Education Development Trust, Itad, University of Leeds Nuffield Centre for International Health and Development, Liverpool School of Tropical Medicine (LSTM), University of Birmingham International Development Department (IDD) and the University of Manchester Humanitarian and Conflict Response Institute (HCRI).

This report was prepared for the UK Government's Foreign, Commonwealth and Development Office (FCDO) and its partners in support of pro-poor programmes. Except where otherwise stated, it is licensed for non-commercial purposes under the terms of the Open Government Licence v3.0. K4D cannot be held responsible for errors, omissions or any consequences arising from the use of information contained in this report. Any views and opinions expressed do not necessarily reflect those of FCDO, K4D or any other contributing organisation.

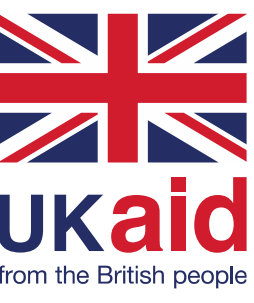

(C) Crown copyright 2020 . 